DOI: http://dx.doi.org/10.4314/ljh.v27i1.7

\title{
The Significance of the Level Tone in Ghanaian English: Evidence from Spoken Discourse
}

\author{
Charlotte Fofo Lomotey \\ Lecturer, Department of Applied Linguistics, \\ University of Education, Winneba, Ghana
}

\begin{abstract}
In Brazil's $(1985,1997)$ discourse intonation model, the level tone is used by speakers to make choices that do not have any real communicative significance within the context of interaction. According to the model, a speaker assigns the level tone in ritualized, unplanned, preplanned, prerecorded, formulaic language, and in reading out. The current study investigates the functions of the level tone in Ghanaian English using Brazil's discourse intonation framework. Data consisting of 13 hours of conversations recorded from 200 Ghanaians were subjected to both auditory and acoustic analyses. Results show that Ghanaians perform other communicative functions with the level tone in addition to what the model posits. Based on the results, it is argued that the level tone performs significant communicative functions similar to the falling or rising tones in Ghanaian English.
\end{abstract}

Key words: level tone, oblique orientation, significance, discourse intonation, Ghanaian English

This paper examines the significance of the level tone in Ghanaian English discourse using Brazil's discourse intonation framework (1985, 1997). In everyday English interactions, speakers use intonation to serve important communicative functions. The particular functions depend on intonational choices that speakers make. For instance, it can be used to indicate information structure, show discourse functions, perform speech act functions, and perform interactive functions (Chun, 2002). Apart from these functions, intonation also has a pragmatic function in that it communicates sociolinguistic information about 
differences in the status of speakers, and whether there is any social distance between them. This sociolinguistic information helps to establish cooperation between interlocutors (Brazil, 1997; Clennell, 1997; Pickering, 2001). Although intonation carries a heavy communicative load, its use may not always help to achieve the desired results. Thus, if not used appropriately, it may cause serious communication breakdown (Gumperz, 1982; Pickering, 1999, 2001).

Accordingly, Clennell (1997) argues that the wrong use of intonation in interactions involving native speakers (NSs) and non-native speakers (NNSs) may result in serious communication breakdown because "(a) the propositional content (essential information) of the message may not be fully grasped, (b) the illocutionary force (pragmatic meaning) of utterances may be misunderstood, and (c) inter-speaker co-operation and conversational management may be poorly controlled" (p. 118). The effect of this is that over time, the NS listener becomes bored with the NNS and eventually abandons the interaction entirely. Apart from marking prominence, Brazil notes that speakers can use intonation by relying on tone choice or key choice. This study focuses on tone choice and the use of tone, which comprises falling, rising or level tone. Specifically, it is restricted to the use of the level tone by speakers of Ghanaian English.

Although tones are important, NNSs have been found to differ markedly from NSs in the use of tones in discourse, and this has the tendency to cause miscommunication. For example, Hewings (1995) compared the intonation choices of British English speakers with those of advanced Indonesian, Greek, and Korean English learners and found out that the learners made use of more level tones and falling tones at points where their British counterparts might prefer rising tones. From this, he concluded that the use of falling tones can communicate deliberate rudeness or animosity. Similar to Hewings' research on L2 learners, the data analyzed for the present study suggest that Ghanaians use the level tone in ways that are both similar to as well as different from how native speakers may use it. These differences notwithstanding, the level tone is significant in Ghanaian English discourse because like the falling or rising tones, speakers use it to convey important pragmatic information which listeners 
process with understanding. The next section discusses the theoretical framework adopted for the study and describes the use of the level tone in English discourse. The third section presents a description of the procedure used to collect and analyze the results. The fourth section discusses the results obtained from the analysis and the final section concludes the paper.

\section{Theoretical Framework}

The theoretical framework adopted for this study is discourse intonation, proposed by Brazil $(1985,1997)$. According to Brazil, the discourse approach to the study of intonation is crucial because intonation carries significant communicative and pragmatic functions that help interlocutors to understand the message encoded in any communicative process. The choices that speakers make are not linked to grammar or attitude, but to the communicative value of the interaction that both speaker and listener share. With reference to this approach, Brazil (1995) suggests that "the communicative value of intonation is related to the purpose that a particular piece of language is serving in some ongoing, interactive event" (p. 240). The ongoing interactive event is centered on a state of convergence between the discourse partners. This state of convergence is "the continuous negotiation toward a roughly mutual state of understanding in the immediate and constantly changing world of naturally occurring spoken discourse that allows for successful communication between participants" (Pickering, 2009, p. 240).

In effect, interlocutors keep negotiating a common ground, that is, the background by which new information is added, and this also depends largely on the context of interaction. This context is determined by the real-time assessment of shared and unshared knowledge between the speaker and hearer. Consequently, all intonation choices arise from the context in which they occur, and not outside of it. The choices therefore present the "here and now" meaning of whatever participants say and show participants" "present" communicative value. There are two pitch choices available to speakers to select from and assign on the prominent syllable(s) within the tone unit. These are pitch movement (or tone choice) and pitch height (or key/termination choice). These choices are used to project both "referential and 
non-referential information" (Pickering, 2009, p. 240), and this information is interpreted by listeners based on their understanding. Brazil's model makes use of three tone types; falling, rising, and level tones.

\section{Discourse Intonation and Oblique Orientation}

In Brazil's model, speakers can create two main types of orientation by exploiting the tonal composition of falling, rising, or level tones. These are direct and oblique orientation. In direct orientation, speakers select tones so that their listeners can understand whether the information is new or recoverable. The use of falling tones to project new information or the use of rising tones to project old information results in direct orientation. It is direct because the combination focuses on how both speakers and listeners assess the information within the context of interaction. Thus, speakers orient towards their listeners to achieve a state of convergence between them. In oblique orientation, on the other hand, speakers employ a combination of falling and level tones. The orientation is oblique because speakers temporarily withdraw from the context of interaction and focus on the language specimen itself rather than their listeners. In this sense, speakers suspend the interpersonal aspect of the discourse and concentrate on what is in the discourse, thereby announcing a linguistic item that is generic (Cauldwell, 2003).

There are different conditions under which speakers may orient obliquely towards their listeners. One such condition is the use of formulaic or ritualized language. In this instance, speakers, mostly teachers, use the level tone to give orders in the classroom. For example, the utterance

(1)
$/ / \rightarrow$ stop WRITing // PUT your PENS down $/ / \rightarrow$ LOOK this WAY

(Brazil, 1997, p. 138)

shows a teacher using "constructed language", communicating the idea as "these are not my words addressed particularly to you on this occasion; they are rather a routine performance whose 
appropriateness to our present situation we both recognize" (Brazil, 1997, p. 136). For Brazil, example (1) represents a situation where both teacher and students are "in a world of timehonoured and well-understood procedures" (Brazil, 1997, p. 138). Another use of the level tone occurs in the classroom with the "template technique" (Brazil, 1997, p. 138). In this technique, teachers start with an utterance and in a bid to solicit information from them, do not finish with the answer but allow students to supply it. An example is shown in (2):

(i) Teacher:

(ii) Pupil:

$/ / \rightarrow$ the CApital of MALI IS // .....

(iii) Teacher:

// p BAMako //

// p GOOD //,

Online linguistic planning is another condition under which level tones can be used. When we speak, the words do not always flow easily. Sometimes, we need to stop for a while to think or plan what to say next. In the course of this, some speakers may like to fill the silent spaces so that their listeners will not take the silence as the end of their utterances. The fillers that are used consist mostly of hesitations. Example (3) illustrates some of these fillers.

\section{$/ / \rightarrow \mathrm{UH} / /, / / \mathrm{UM} / /, / / \mathrm{AND} / /$}

Another condition under which speakers may employ oblique orientation is when they read out, which is also called reading intonation (Brazil, Coulthard, \& Johns, 1980). In this particular activity, similar to the views held by Brazil (1997), Brazil, et al. (1980) assert that speakers can either read as if they were speaking or they can stand outside of it saying "this is what the text says" (p. 83). For this reason, speakers are said to place the linguistic organization of the text over and above the relationship between their tone choices and the state of convergence between them and their listeners. This is illustrated in example 4 below:

(4) $/ / \rightarrow$ what i KNOW of $\underline{\text { THIS }}$ was $/ /[0.25] / / \rightarrow \underline{\mathrm{UH}} / / \rightarrow$ the GOVernment actually $\underline{\text { PLANNED } / / ~} \rightarrow$ to expAND 
infrastructures// $\boldsymbol{Y}$ but unFORtunately $/ /[0.78] / / \rightarrow$ he LOST power $/ /[0.61] / / \rightarrow$ and $\underline{\mathrm{UHM}} / /[0.16] / / \rightarrow$ our $\underline{\mathrm{NEXT}}$ government $/ /[0.90] / / \rightarrow$ THOUGHT $/ /[0.82] / / \rightarrow$ exPANding infras-infrastructure won't be the case // $y$ so he $\underline{\mathrm{HAS}}$ to // [0.33] // ybring it BACK //

In this conversation, a speaker recounts a known fact that one government established senior high school (SHS) and another government came and increased the number of years that students will spend in school. He adds that the latter government had the intention of increasing facilities in the schools, but unfortunately, it lost the election. This information provided here is not new; that is, it is not the speaker's own words, rather, it is public knowledge. Thus, while he speaks, he only reads what is in existence. The tonal composition is largely level, with only 3 falling tones. Two of the falling tones accomplish important functions. The first sets off a point of adding increments (cf. O'Grady, 2010; Ono \& Couper-Kuhlen, 2007; Walker, 2004), a way of grammatically extending his prior units. For instance, there is a point of completion on the tone unit government actually planned to expand infrastructure. He then starts another utterance but unfortunately, he lost power while the second closes the entire utterance.

In sum, the level tone is used by both native and non-native speakers to perform different functions in English discourse. It has also shown that while speakers choose some tones (e.g. falling and rising), they may also opt for a combination of level and falling tones to create an oblique orientation, showing that they are planning what to say, using ritualized or formulaic language, or reading out a text. It is thus argued that if the level tone can be used in any of these circumstances, then speakers of Ghanaian English, the variety of English spoken in Ghana, can be expected to use it under some or all of the conditions outlined above.

Although there have been some important studies on the pronunciation of Ghanaian English (e.g. Adjaye, 2005; Koranteng, 1992, 2006) and its peculiarities, none of these discuss the use or function of the level tone in this variety. The present study is therefore significant in that it is the first comprehensive study that applies Brazil's theory to examine the level tone in 
Ghanaian English. It is recognized that there are various varieties of Ghanaian English. However, the present study focuses on the variety that Sey (1973) refers to as Educated Ghanaian English. The results contribute to the understanding of how Ghanaians use this particular tone in their everyday interactions. The results also increase our understanding of the features of Ghanaian English pronunciation. Apart from these, the study contributes to the ongoing discussion of the linguistic features of Englishes, especially those in the outer circle (Kachru, 1996), and lead to a better understanding of world Englishes. The study seeks to answer the following research questions:

(a) What functions does the level tone perform in Ghanaian English discourse?

(b) Based on the functions, what is the significance of the level tone in Ghanaian English discourse?

\section{Research Design}

\section{Data and Methodology}

The research design adopted for the present study is qualitative in nature. According to Denzin and Lincoln (2002), a qualitative research design provides a deeper analysis and allows the researcher to show a richer and an in-depth understanding of how people make meaning of their situation or interpret phenomena. Since the study involves the identification and interpretation of an intonational pattern, a simple analytical descriptive method was employed.

\section{Population and Sampling}

Best and Kahn (2006) observe that population is a group of individuals that have one or more features in common and are of interest to the researcher. Creswell (2013) also notes that the population should be the group of interest to the researcher to which he/she would like the results to be generalizable. The entire population for the study comprised all students of the public university where the research took place. However, since it was not possible to work with the entire population, only one group of students was selected. Thus, the sample for the study comprised 
students studying Ghanaian languages in this university. A simple random sampling was used to select the participants. This is because each of the students had an independent and equal chance of being selected. In all, 200 speakers of Ghanaian English were recruited for this study. These were students of a public university in Ghana who speak and study all the major Ghanaian languages at the university level. The participants were made up of 100 males and 100 females aged between 18 and 40 years. The languages studied by these students constitute about $96 \%$ of the entire Ghanaian population (Ghana Statistical Service, GSS 2012). The languages these students speak and study are Akan, Ewe, GaDangme, Nzema, Dagbani, Gonja, Dagaare, Gurene, and Kasem (see Table 1).

All participants are fluent in their native languages and use English as a second language because they all indicated that they started learning English when they entered primary school at age 6 , after they had already started speaking their native languages. Students were chosen based on the fact that they have had (and continue to have) instruction in English at all levels of their education and use it also for different classroom strategies, e.g. in pair /group work or conversations. As regards their English proficiency levels, participants rated it as between intermediate to high. Although all the participants were recruited verbally, precautions were taken to ensure that only students of Ghanaian languages participated in the study, thereby excluding English or French students in order to prevent them from carrying over their knowledge of English or French intonation systems into the conversations. Again, no participant had any speech or hearing impairment that could have affected the quality of data obtained. The number of students and their languages are presented in Table 1. 
Table 1

Number of students and their languages

\begin{tabular}{lccccccccc}
\hline Language & Akan & Ewe & $\begin{array}{l}\text { GaDang } \\
\text { me }\end{array}$ & $\begin{array}{l}\text { Dagb } \\
\text { ani }\end{array}$ & Gonja & Nzema & Dagaare & $\begin{array}{l}\text { Kase } \\
\mathrm{m}\end{array}$ & $\begin{array}{l}\text { Gure } \\
\text { ne }\end{array}$ \\
\hline Male & 15 & 15 & 10 & 10 & 10 & 10 & 10 & 10 & 10 \\
Female & 15 & 15 & 10 & 10 & 10 & 10 & 10 & 10 & 10 \\
\hline Total & 30 & 30 & 20 & 20 & 20 & 20 & 20 & 20 & 20 \\
\hline
\end{tabular}

\section{Data Collection}

This study is part of a larger study on the discoursal functions of intonation in Ghanaian English. Because the students were 18 years and above, their consent was sought directly from them. After they had agreed to take part by signing the consent form, they were asked to provide short biographic data. These included their level of proficiency in English and other Ghanaian languages that they spoke. They were then grouped according to their languages. Each group consisted of five people and altogether, 40 groups were created. Each person took part only once in the conversation to ensure that there was no duplication. The members of each group sat around a large conference table in a quiet room. The recordings were done on campus. However, the room chosen was isolated from all the other classrooms. The room was originally created for Home Science practical work, but the programme is no longer offered in the university so it is used as a resource room for students with disabilities. It is open only when it is time for examinations these students may use it for the writing of papers. Because of its location within the school, the room is very quiet at all times. In fact, it was actually based on the quietness that it was selected for the recordings. All recordings took place in the morning between 8 am and 11 am for seven days. Once the group members had indicated their readiness, they were presented with a prompt on an issue of national interest, which is the duration of senior high school (SHS) education.

The rationale for choosing the topic was to solicit the views of students, albeit in an informal manner. The students who took part in the study belonged to 2 main categories; those who did a 3-year SHS and those who did a 4-year SHS. As such, they 
were better placed to share their experiences than those who belong only to the 3-year or 4-year duration. Participation was voluntary, and no student was coerced or enticed with any form of reward. Once they had read through the prompt and understood it, the recording began. The data were collected with a Sound Grabber II PZM Condenser Microphone connected to an Olympus digital voice recorder and placed in the middle of the table around which they sat. There was no other person except the participants left in the room. The room was very quiet to enable the microphone to capture only the voices of the participants, and not any outside noise. This also produced high-quality recordings. Each recording session lasted 20 minutes. In total, 13 hours 20 minutes of data were obtained from all 40 groups.

\section{Data Analysis}

The data were transcribed using both auditory and acoustic means. First, the data were played back to facilitate orthographic transcription $^{3}$ and for prominent syllables to be marked. After the orthographic transcription, the data were transferred onto the computerized speech laboratory (CSL) for acoustic analysis. The utterances were segmented into tone units using Brazil's criteria. Although there are different features that may be used to demarcate tone unit boundaries (DuBois et al., 1992), Brazil's model recognizes pitch movement, pause, or coherent contour as phonetic features for the segmentation of tone units. In the present study, tone units were separated from one another using pause structure, a distinct pitch movement, or a coherent contour whenever they were present within

the data. This also resulted in the presence of incomplete tone units and multiple prominent syllables in the data. The tone unit segmentation was followed by fundamental frequency (pitch) measurement for all prominent syllables identified and pause duration measures. Lastly, tones (pitch movement) were identified and marked on all the prominent syllables.

3 Transcription Conventions are shown in Appendix A 


\section{Test of Reliability}

After the analysis, samples of the transcriptions (25\%) were independently cross-checked for tests of transcriber reliability. This was to assess the level of agreement in order to ensure that tone units, prominent syllables, and pitch movements were properly marked. In consonance with similar studies (e.g. Cheng, Greaves, \& Warren, 2008), the samples were rigorously checked and rechecked by a trained phonetician with 15 years of experience who has worked extensively with the systems within Brazil's model. The transcriber agreement was $89 \%$ for prominent syllables and $90 \%$ for tone marking. These figures are very good because it is not easy for trained listeners to establish agreement in intonation marking (Cauldwell \& Allen, 1997).

\section{Results and Discussion}

There were 9841 tones identified in the entire data. Out of these, 2088 level tones representing $21 \%$ of the total number of tones. Table 2 is a summary of the distribution of tones in the data for all the 200 participants.

\section{Table 2}

Distribution of Tones in the Data

\begin{tabular}{lllll}
\hline Tone choice & Fall & Rise & Level & Total \\
Number & 7554 & 199 & 2088 & 9841 \\
Percentage (\%) & 77 & 2 & 21 & 100 \\
\hline
\end{tabular}

The table shows a predominance of falling tones. However, the present discussion will limit itself to the occurrence of level tones, which has the second highest number in terms of frequency. The analysis for the present study revealed that the level tone used is similar to the systems proposed in Brazil's model (e.g. in reading intonation, preplanning/hesitation) and different from what might be expected (e.g. in retelling). The following sections present instances where Ghanaian English speakers used the level tone similar to the proposed systems in the model and follow with a discussion of the level tone in ways that present an exception or difference to the systems in the model. 


\section{Level Tones and Oblique Orientation}

As already indicated, the level tone is mainly employed in oblique orientation. That is to say that, instead of packaging their utterances to reflect either as part of the common ground or an addition to it, they rather focus more on the language material that they have. Thus, the choices they make do not have any communicative significance within the context of interaction. The level tone was used in the following ways:

Lists: The analysis revealed that speakers used the level tone in the construction of lists. According to Schiffrin (1994), a list represents a way in which a speaker organizes a category into items that are the same in some ways, but different in other ways. Items in a list in English have a fixed pattern. For example, Bowler and Parminster (1992) affirm that "the intonation always goes down on the last item (to show that the list is finished), and up on all the items that come before the last (to show that there is more to come)" (p. 30).

Usually, rising tones are employed on items in lists to show their continuative functions. However, there is evidence to suggest that it is not only the rising tone that communicates continuation (or incompleteness) in a list, but also, the level tone does. Within the conversations, speakers marked non-final items in lists with the level tone until they got to the end where they assigned the faling tone to show finality. Figure 1 illustrates instances where speakers used the level tone on lists. 
1. Sp 1:// $\rightarrow$ uh in TERMS of $/ /[1.00] / / \rightarrow$ proficienCY $/ /[0.29] / /$

2. $/ \rightarrow$ acadeMI:CS $/ / \rightarrow$ reSULTS and then $/ /[0.12] / /$ yALL sort of

3. THINGS //

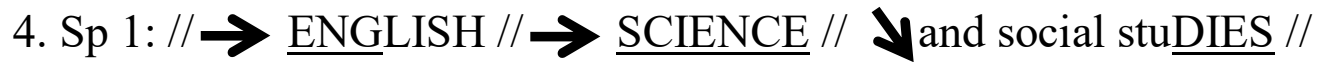

5. Sp $2: / / \rightarrow$ the SCIENces $/ /[0.28] / / \rightarrow$ the ENGlish $/ / \rightarrow$ the $\underline{\text { MATHS } / /}$

6. // sometimes is the SOcial //

Figure 1: An extract showing lists

In Figure 1, speaker 1 assigns a level tone to the items in the list, that is, proficiency, academics, and results. Similar instances are also shown with speakers 1 (different from the first speaker 1) and 2 listing the items English, Social Studies, Maths, and Science. In all the examples, we notice that the speakers use the level tone on the items that come before the last one and then assign a falling tone to the last item to show finality. This use of the level tone is a way of showing continuity (Cauldwell, 2003), that is, there is more to come, akin to the use of the rising tone on list. In this particular use, the level tone, rather than being ritualistic, shows a similarity with what might be expected in inner circle Englishes. For example, the level tone has been found to be ritualistic in lists (Cauldwell \& Hewings, 1996). Cauldwell and Hewings observe, for example, that the train station announcer has repeated the same words in the announcement so often that he no longer bothers about perceiving them as new or old information. They cite the following as exemplified in (5):

5) the train on platform three will call at $/ / \rightarrow$ Peterborough $/ \rightarrow$ Ely // March // ע and Cambridge // $\quad$ (p. 330)

and note that "... categorizations have become ritualistic, because they have often been said in the same particular context by the same speaker" (p. 330).

Verbal Planning: From the analysis, another use of the level tone identified is in verbal planning. Brazil observes that 
there are situations where speakers do not achieve encoding and in such cases, this presents a difficulty for them. The difficulty arises from the fact that because speakers keep thinking of what to say next, they encounter momentary coding problems and as a result, tend to use a lot of pauses and pause fillers. According to Brazil (1997), the pauses and fillers are an indication that the speaker is "thinking on his/her feet" (p. 140). This assertion implies that there is a problem with the organization of the message such that the speaker moves away from focusing on the state of convergence between him/her and their listeners, to focusing on the linguistic properties of the utterance itself.

In Figure 2, the speaker assigns level tone to his second tone unit, one and follows it with a pause of [0.38 secs] (line 1) before saying what he actually wants to say. Readers note that the speaker does not want to say one. However, he realizes that he is finding difficulty in continuing. The use of the level tone, together with the substantial pause, is an indication that the speaker is experiencing some momentary coding problems. After the pause, he remembers the word and then produces it appropriately. A similar instance occurs in line 4 where the speaker continues but gets stuck at a point.

\begin{tabular}{|c|c|}
\hline 1 & $/ /$ y MOST of them FAILED $/ / \rightarrow$ ONE $/ /[0.38] / /$ yi ASKED \\
\hline 2 & some of them // $y$ and the er they WHAT they told me was that er // \\
\hline 3 & {$[1.19] / / Y$ ACtually $/ / Y$ they LEARNED $/ / \mathrm{i}$-is not that they did not } \\
\hline 4 & learn they were $/ / \rightarrow$ BUT $/ /[0.24] / / \rightarrow$ they were not able to \\
\hline 5 & FInish // [0.84] // YTHEY were not able to FInish // [0.15] \\
\hline
\end{tabular}

Figure 2: An extract showing instances of verbal planning

He appears to have forgotten what he wants to say after but and that results in the $[0.24 \mathrm{sec}$.] pause. The level tone on but signifies that he is having a problem with exactly what to say next. Right after the pause, he is able to produce the statement, but he still employs a level tone to the whole tone unit. A close look at they were not able to finish suggests that the speaker is not sure that he 
is saying the right thing, and this is followed with a long pause and then he confirms his utterance with a repetition of the previous tone unit. The confirmation (line 5) also lends credence to the fact that the speaker was unsure of what to say initially.

The last and final extract showing an instance of verbal planning is presented in Figure 3. Here, a speaker starts by signaling that he will tell his colleagues something.

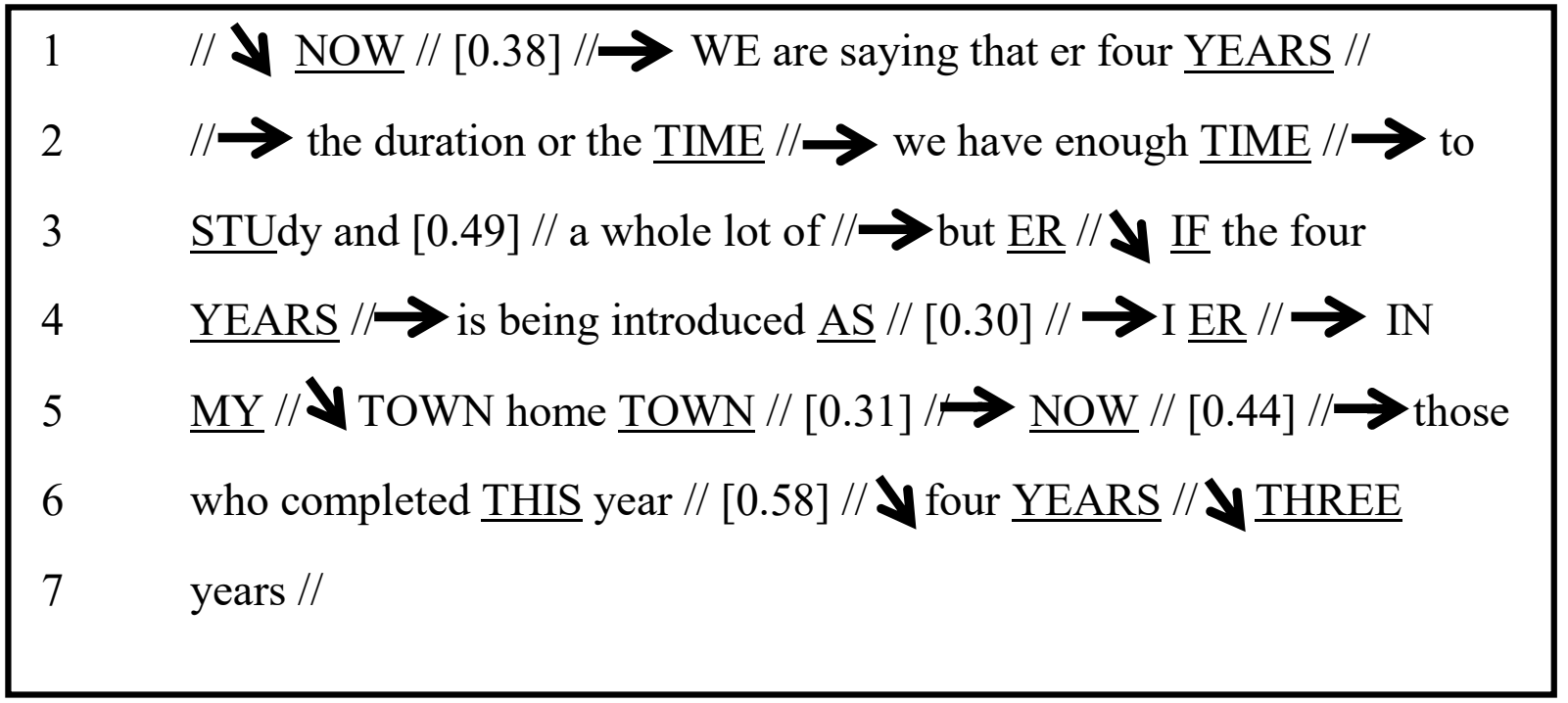

Figure 3: An extract showing instances of verbal planning

As his submission ensues, it becomes obvious that he is still missing some information. This necessitates his use of a pause of [0.38 secs] after now followed by level tones on the second, third, fourth, fifth, and seventh tone units. The level tones on we are saying that er four years shows that the speaker has not finished his statement and needs to add more information to complete it. The same can be said of the tone units from the duration or the time to (line 2) but er (line 3).

The whole stretch from the second to the seventh tone unit shows that the speaker is encountering some problems with the exact words to use. Because of the presence of more level tones (10 as compared to 5 falling tones), the whole of the extract appears incomplete as the speaker constantly seems to be looking for the words to finish it. As the speaker struggles to produce the words he also pauses at some points where he might not be 
expected to do so. By assigning level tones, the speaker tries to recollect or remember his words, to organize his thoughts and to plan his verbal content so as to complete the utterance.

It is important to note that a speaker may use less number of level tones (Figure 2) as against more (as in Figure 3) to show a process of verbal planning. What is important is the role of the level tones in a particular tone unit, and not necessarily the number. When Figure 2 is compared to Figure 3, one realizes that there are more level tones in 3 , but in each case, there is verbal planning taking place. It might appear that the speaker's pauses are irrelevant; however, this may not be the case. He appears to use the pauses as wait times to allow his listeners to focus their attention on him before he continues talking.

Hesitation: Speakers used a lot of hesitation markers in their conversations. These markers are part of a group of filled pauses. In all, the data consisted of both lexical and non-lexical fillers. The lexical fillers are hesitation markers and false start devices. The hesitation markers are $e r$ and $u h$. Because hesitation markers (and all other filled pauses) "act as points in the stream of speech where speakers dwell (in the sense of wait) for a short time while making a non-word" (Cauldwell, 2013, p. 85), they allow speakers have some time to think while also deciding on what to say next. By their nature, Cauldwell (2013), as well as Pickering (1999), argues that filled pauses "almost always occur with a level tone" (Cauldwell, 2013, p. 85). Following this, all hesitation markers produced as prominent syllables in the data were marked with level tones.

Figure 4 is one instance of the use of hesitation markers by a speaker. In a manner similar to verbal planning, speakers produced hesitation markers when speaking. There are hesitation markers in lines 2, 4, and 5 and in all cases, they appear as the only syllables in their respective tone units. The hesitation marker in line 2 is preceded by a pause which is "a common occurrence" (Cauldwell, 2013, p. 85).

Both the pause and the hesitation marker are a way of helping the speaker to buy himself some time to decide on what to say next. The other markers (lines 4 and 5) have vowel lengthening on them. This lengthening is also to allow the speaker enough time to think of what to say, although it slows down the 
entire tone unit. The more a speaker lengthens the word, the more time he/she has to plan the next word.

\section{Y there has been the $\underline{\mathrm{NEW}} / / \mathrm{Y} \mathrm{reFORM} / /[1.12] / /$ Yof THESE er what // \\ $2[0.20] / / \rightarrow \underline{\text { ER }} / / \mathbf{Y}$ Jhs $/ /[0.25][\mathrm{hh}] / / \rightarrow \underline{\mathrm{AND}} / /[0.21] / / \mathbf{Y}$ and the}

3 RATIOna:le be $\underline{H I N D}$ this $/ /[0.10] / / \rightarrow$ jhs was DIFFerent from $\underline{\text { THOSE }} / /$

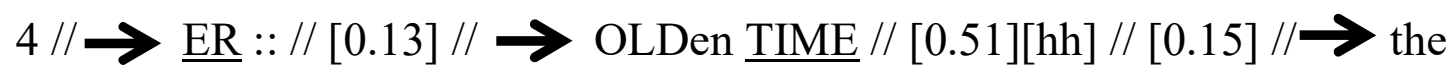

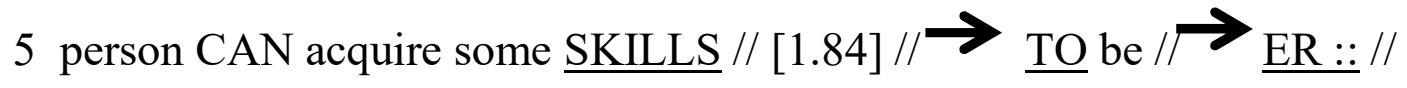

$6 / / \rightarrow$ Able to dePEND $/ /$ Yon him $\underline{\operatorname{SELF}} / /[1.76] / /$

Figure 4: An extract showing hesitation markers

What actually happens is that the rhythm is suddenly interrupted, the speed is slowed to enable the speaker wait and think about something before proceeding with the discourse. In other words, the speaker uses the pause and the lenghtening as a "stepping stone" (Cauldwell, 2013, p. 85). Cauldwell observes that a filler serves as a stepping stone "where the rhythm is interrupted, the speed slows and the speaker dwells on a word which is advancing the discourse" (p. 86).

Reading Intonation: As already indicated, the level tone is used in reading intonation. This is another way by which speakers orient obliquely to their listeners. Brazil, Coulthard, and Johns (1980) argue that speakers can either perform reading as if they were speaking or stand outside of it saying "this is what the text says" (p. 83), thereby reading out the text. In this circumstance, speakers place the linguistic organization of the text over and above the relationship between their tone choices and the state of convergence between them and their listeners. An instance of such reading is found in Figure 5.

In the extract, the speaker adopts a reading intonation to provide information as if reading from a text. She basically reads the government's vision for establishing the junior high school (JHS) assigning more level tone (8) and fewer falling tones (3) and 
rising tones (2). It should be noted that it is not only level tones that are employed in oblique orientation, but the presence of multiple prominences also results in oblique orientation.
$1 / / \mathbf{Y}$ the REAson why there is WHOLEsale $/ /[0.26] / / \rightarrow$ is because we

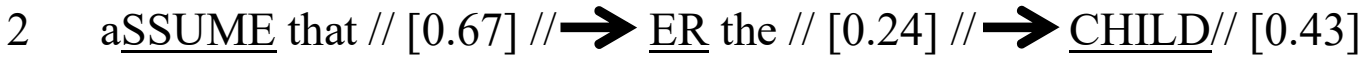
$3 / / \rightarrow \underline{\text { ERM }} / / \pi$ will $\underline{\text { LEARN } / /} \rightarrow \underline{\text { SOMEthing } / \rightarrow \text { beCAUSE they }}$
$4 \underline{\mathrm{THESE}} / /$ บ $\underline{\mathrm{ER}} / / \rightarrow$ basic er reFORM this thing $/ \rightarrow$ that they
5 INtroduce that //Ywe should USE //Ywe should be creaTIVE//
$6 \quad[0.27]$

Figure 5: An extract exemplifying reading intonation

The speaker's opening statement the reason why there is wholesale is because we assume that er the child erm will learn something breaks at wholesale with a falling tone, and then completes the utterance with a level tone at something. The use of the rising tone is to remind (Cauldwell, 2003) her colleagues of the rationale for the new educational reform. Three (3) of the 8 level tones are marked on hesitations due to the fact that she may be encountering momentary coding problems. The effect of the heavy presence of level tone is that the speaker is only recounting what is already in existence, and not a statement she is making by herself.

Figure 6 represents another instance of reading intonation. In this extract, the speaker adopts a lecturing tone on the rationale for establishing both the JHS and SHS. Again, this is common knowledge, and so she presents it as if she was reading a prerecorded message. She combines more level tones (13) with falling tones (9) to show an oblique orientation to the material. 
$1 / /$ Yer in SOME way i don't a GREE with you / $\mathbf{y}$ there has been the NEW

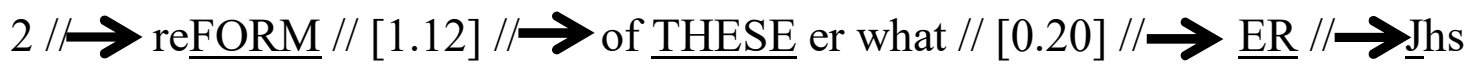

$3[0.25][\mathrm{hh}] / / \rightarrow \underline{\mathrm{AND}} / /[0.21] / / \rightarrow$ and the RATIOna:le be $\underline{\mathrm{HIND}}$ this $/ /$

$4[0.10] / / \mathrm{jhs}$ was DIFFerent from $\underline{\mathrm{THOSE}} / / \boldsymbol{y} \underline{\mathrm{ER}} / /[0.13] / / \rightarrow$

5 OLDen // ע $\underline{\mathrm{TIME}} / /[0.51][\mathrm{hh}] / / \boldsymbol{\wedge} \underline{\mathrm{NOW}} / /[0.16] / / \mathbf{Y}$ the $\underline{\text { SETting up }}$ 6 of the $/ /[0.31] / / \mathbf{Y}$ Jhs er the BAsic level $/ /[0.29] / / \boldsymbol{\pi}$ is to $\underline{\text { TRAIN } / / \rightarrow}$ 7 and eQUI:P the child //Y so that Even at the basic level $/ /[0.15] / / \rightarrow$ the

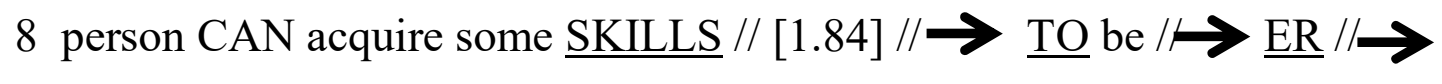
9 Able to dePEND $/ /$ Yon himSELF $/ /[1.76] / / \mathbf{Y}$ you underSTAND me $/ /$

Figure 6: An extract exemplifying reading intonation

The extract also shows that eight tone units occur with hesitations, indicating that the speaker does a lot of online verbal planning in her utterance.

Level Tones and Retelling: In this particular use of the level tone, speakers show an exception to what might be expected within the model. Typically, speakers use the falling tone to project new information or to signal that you don't know this, I am telling you. However, the analysis showed that it is not only the falling tone that speakers used for this function, but also, the level tone, especially in instances where the information has already been provided and it is being repeated. Thus, they retell or recount personal experiences or to communicate their views on an issue. I argue that while speakers read known facts using a combination of falling (and sometimes rising tones) and level tones as might be expected in inner circle contexts, the combination of these same tones creates an oblique orientation in retelling where on the 
contrary, a combination of falling and rising tones might be expected in native Englishes.

Figure 7 is a typical example of an oblique orientation in a telling discourse. In the previous conversation, the speaker argued in favor of the four-year SHS program because he believed that students would have ample time to learn. His argument was countered by other speakers and they disagreed, claiming that the three-year program was better than the four-year period. The conversation continued, and this same speaker takes the floor again and adopts a lecturing tone to voice his opinion. His first utterance starts on a falling tone. The typical oblique orientation is felt where there is a level tone at a potential completion point: $I$ beg to differ, I beg to differ in this your argument. He then assigns a falling tone on years at an actual completion point, and three years is three years.

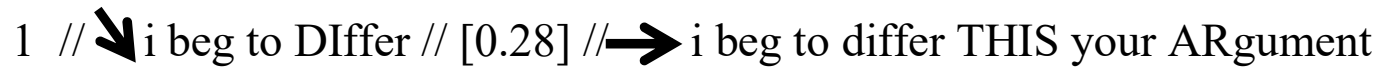
$2 / /[0.19] / /$ in FACT my sister $/ /[0.12] / / \rightarrow$ i will $\underline{\text { NOT } / / \rightarrow \text { aGREE }}$ to 3 what you're saying $/ /[0.80] / / \rightarrow$ beCAUSE $/ /[0.78] / \mathbf{Y O U R}$ years 4 is four years // [0.72] // $\mathbf{y}$ and THREE years is three YEARS // [1.27]// $5 \underline{\mathrm{NOW}} / /[0.25] / / \mathbf{y}$ there are SOME $\underline{\mathrm{SCHOOLS}} / /[0.11] / / \rightarrow$ WHERE 6 there are Even $/ /[0.68] / / \rightarrow$ ER about // [0.39]// $/$ a school which is 7 supposed to have about er TEN teachers // [0.84] // Y they are FEW // [0.42]

$8 / /$ YSO IN this case $/ /[0.33] / / \rightarrow$ STUdents will HAVE to str // [0.15] //

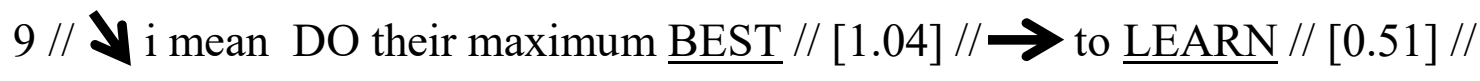
$10 / /$ NOW // [0.19] // IT means they ARE overSTREtching them //

Figure 7: An extract exemplifying a telling discourse

The rest of the presentation is organized with more falling tones on nuclear syllables, an indication that the utterance is a telling one, until he completes his utterances. However, the presence of level tones ( 8 out of 20) shows that the speaker orients more towards the text rather than to his listeners. 
Figure 8 represents another speaker who makes heavy use of level tones in retelling. The exchange starts with one of the speakers suggesting that four years are enough for the students. He further argues that the students will have sufficient time to finish the syllabus and also be able to understand the subjects better than if they go for three years. Another speaker refuses this assertion and adds that it is not enough to enroll people in school without providing the necessary facilities. To this end, she urges the government to consider improving on existing facilities as well as providing new ones.

\begin{tabular}{|c|c|}
\hline 1 & $/ / \rightarrow$ because at TIMES I THINK // maybe SOME schools especially // \\
\hline 2 & {$[0.34] / / \mathcal{Y}$ the rural Areas $/ /[0.18] / / \rightarrow$ even the THREE YEARS } \\
\hline 3 & {$[0.31] / / \rightarrow$ SOME headmasters find it diffiCULT to $/ /[0.31] / / \rightarrow$ get } \\
\hline 4 & classroom for ALL the three this things $/ /[\mathrm{hh}][0.11] / / \rightarrow$ BUT at TIMES \\
\hline 5 & {$[0.66] / / Y$ when you GO to $\underline{\mathrm{THE}}: / /[0.73] / / \mathbf{Y}$ the this thing the } \\
\hline 6 & 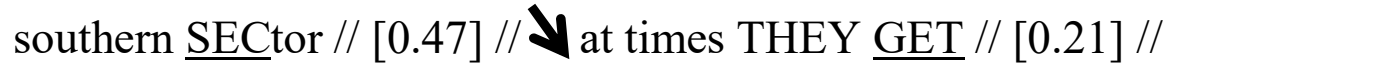 \\
\hline 7 & MORE infrastructure // $y$ THAN the rural Areas // [0.39]// $\mathrm{A}$ \\
\hline 8 & situation WHERE the headmaster is finding it // $\mathbf{y}$ difficult to GET // \\
\hline 9 & {$[0.24] / /$ classrooms for ALL the three YEARS $/ /$ Yand then they are } \\
\hline 10 & 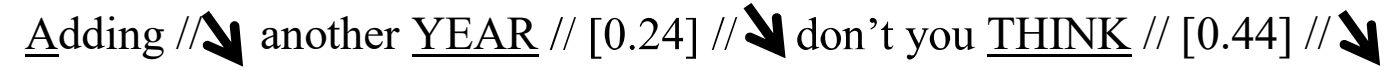 \\
\hline 11 & it will $\underline{\mathrm{BE}} / /[0.42] / /$ something different // [1.39] \\
\hline
\end{tabular}

Figure 8: An extract exemplifying a telling discourse

The speaker adds that she believes that while the extension may be useful for some schools, it may be problematic for others because schools in the rural areas suffer in terms of staffing, accommodation, and other logistics. There are more proclaiming tones (12), suggesting that this speaker is telling something to people who might have no knowledge of such facts. However, her use of level tones (6) shows that she is orienting more towards the material than thinking about how her listeners will interpret the 
information. For instance, there is a level tone at a potential completion point, get classrooms for all the three this things, an indication that the speaker could have stopped at this point of the utterance. With this usage, it can be argued that the speaker completes her statement using a level tone, rather than a falling tone as might be expected. At an actual completion point at times they get more infrastructure than the rural areas, the speaker assigns a falling tone.

Finally, an example of retelling is presented in Figure 9. In the conversation prior to this, a speaker said that the government has not done anything substantial to support the four-year SHS program.

\footnotetext{
1 // SOMEthing someTHING that $\mathrm{i}$ try to // $[0.67] / /$ DIGEST $/ /$ and $\mathrm{i}$

2 realize that $/ /[1.18] / /$ y UNder $\underline{\text { NO }}$ circumstance $/ / \rightarrow$ will a

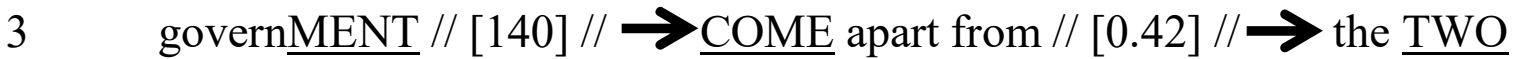

$4 \quad[0.57] / /$ political $\underline{\text { PARties } / / \rightarrow \text { we've been exPEriencing } / / \rightarrow \underline{\text { LEFT }}}$

5 and right $/ /[\mathrm{hh}] / / \rightarrow$ IF the left $\underline{\text { COMES }}$ then the right $/ /[0.70] / / \boldsymbol{Y}$ GETS

6 to minority and what have you i realize that $/ /[0.24] / / \mathbf{Y} \underline{\mathrm{IF}} / / \mathbf{Y}$ any political

$7 \quad$ PARty being the THIRD $\underline{\mathrm{ONE}} / / \rightarrow$ that will come $\underline{\mathrm{IN}} / / \rightarrow$ there will be

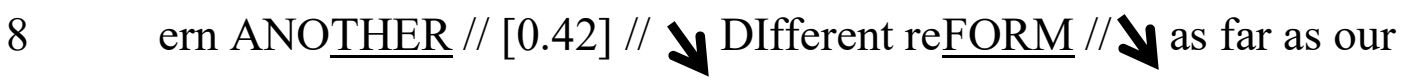

9 educational system is concerned betCAUSE // [1.49] // ע it GOES down into

10 the good books of this country // $\mathbf{y} \underline{\mathrm{THAT}} / /[0.28] / / \mathbf{Y}$ this political party

11 was Able to $/ /[0.38] / / \rightarrow$ CHANGE our educational $/ / \rightarrow$ SYStem from

12 THIS to THAT // [0.40] // $\mathbf{Y A N D}$ to them is a PLUS // [0.24]// $\mathbf{Y}$ on their

$13 \underline{\mathrm{SIDE}} / /[0.40] / / \mathbf{Y}$ and when they are GOing to // [0.24]// Y er campaign it

14 is that oh when we came we were able to DO this //
}

Figure 9: An extract exemplifying a telling discourse 
He lamented the state of schools and claimed that the syllabi for the three-year program were not modified when the one year was added. He added that students had to learn the core subjects for two years before they started learning the electives. In his opinion, students should be allowed to go to school for only three years because they will excel without an additional year. The other speakers agreed with him and the conversation ensued. At this point, another speaker takes the floor and makes his submission. He suggests that politicians are all the same and so there is no need to worry about them. He says that the two parties will continue to rule the country, and that the presence of a third party will not change the political landscape. To him, every political party always wants to score cheap political points with their decisions.

The number of falling tones (15) in this extract is more than the number of level tones (11). This concentration of falling tones, coupled with the information (mostly assertions), indicates that this speaker is proclaiming something, an expectation that he will orient directly to his listeners. However, his mode of delivery suggests that he appears to be more interested in the language of his message than in his listeners. For instance, his opening statement something something that i try to digest ends on a level tone at the two political parties we've been experiencing left and right. After this, the second statement concludes with a falling tone on able to change our educational system from this to that, exhibiting typical features of oblique orientation, that is, level tones, as well as multiple prominent syllables, in some tone units (Brazil, 1997).

From the utterances (Figures 7, 8,9), it can be seen that the number of level tones in each case is smaller than that of falling tones. For example, there are $40 \%$ of all tones in Figure 7, 33\% in Figure 8 , and $42 \%$ in Figure 9, respectively. As a result, one may be tempted to assume that the level tones do not contribute anything. However, this is not the case. In fact, one realizes that in most places where level tones occur, the speakers mean to provide some information, and not merely on hesitation or for verbal planning. Based on this, Figures 7, 8, and 9 are shown to illustrate how different speakers used the level tone to retell given information. 


\section{The significance of the level tone}

The analysis has revealed that there are ways in which speakers of Ghanaian English use the level tone to perform functions similarly to the systems proposed in Brazil's model. These include its use in lists. In this instance, speakers use it a continuative tone, similar to the rising tone. Verbal planning is another instance in which speakers make use of level tone. Here, they use the level tone to serve as wait time, especially in cases where they encounter difficulty in producing the exact words for the continuation of their utterances. Most often (though not in all cases) the words that are assigned level tones occur with some substantial amount of pause before or after the word. As in verbal planning, speakers also assigned level one to hesitation markers (lexical filled pauses) so as to allow them some time to think of what to say next. The final instance in which speakers use the level tone similar to the model in reading intonation. With this use, they produced their utterances the same way they read out text from a book, an indication that they are not producing the words by themselves, but are just reproducing common knowledge that all participants can relate to.

The analysis also showed that speakers use the level tone to perform functions in places where mostly falling (and to some extent) rising tones might normally be expected in Brazil's model. The activity in this instance can be termed retelling because speakers clearly show they are providing information which has already been provided. When this happens, the speaker is expected to use a combination of rising and falling tones, not level tones. Although they used a lot of falling tones in such instances, the presence of a fair amount of level tones in these extracts created the impression that the speakers were orienting obliquely, rather than directly, towards their listeners.

It is interesting to note that a high frequency of level tones in utterances may not be peculiar to Ghanaian English alone. It has been found to perform important communicative functions just like the falling and rising tones in some nativized varieties, such as Singapore and Malaysia Englishes (Goh, 1994, 1998, 2005), and learner varieties such as English spoken in Indonesia (Hewings, 1995). For instance, Goh (2005) argues that all intonational choices have accompanying communicative purpose 
in Singapore English, and the level tone is no exception. She further observes that the selection of the level tone depends on what meaning speakers wish to convey. On the basis of this finding, she concludes that the systems within Brazil's model do not always have the same communicative value for the English spoken in Singapore. The findings from the analysis in the present study confirm Goh's assertion that the level tone is more than just a linguistic construct.

\section{Conclusion}

The study has revealed that the level tone is used in Ghanaian English to perform functions in consonance with Brazil's model as well to perform functions differently from what might be expected in the model. While the uses that meet expectation may not present any new evidence in this variety of English, the level tone in retelling information suggests that it is significant. It shows that it is not always that the level tone has little communicative value, that "the speaker is not making a genuine attempt at communicating" (Goh, 2005, p. 109), but that it can be used in place of the falling or rising tone. The choice of level tone in such instances suggests that speakers' communicative intent may be different from what Brazil's model proposes. In fact, during interactions, these speakers make moment-by-moment decisions about their speech and the meaning their listeners derive from it. In conclusion, it is argued that in Ghanaian English, the level tone is highly significant just like the falling and rising tones, and that Ghanaians may not always use it to perform the same functions as the proposed systems in Brazil's discoursse intonation model. 


\section{References}

Adjaye, S. A. (2005). Ghanaian English pronunciation. New York, NY: The Edwin Mellen Press.

Best, J. W., \& Kahn, J. V. (2006). Research in education $\left(10^{\text {th }}\right.$ ed). Boston: MA: Pearson Education.

Bowler, B., \& Parminster, S. (1992). Headway pre-intermediate pronunciation. Oxford, UK: Oxford University Press.

Brazil, D. (1985). The communicative value of intonation. Birmingham, UK: English Language Research.

Brazil, D. (1995). A grammar of speech. Oxford, UK: Oxford University Press.

Brazil, D. (1997). The communicative value of intonation in English. Cambridge, UK: Cambridge University Press.

Brazil, D., Coulthard, M., \& Johns, C. (1980). Discourse intonation and language teaching. London, UK: Longman.

Cauldwell, R. (2003). Streaming speech. Birmingham, England: Speechinaction.

Cauldwell, R. (2013). Phonology for Listening. Birmingham, England: Speechinaction.

Cauldwell, R., \& Allen, M. (1997). Phonology. Birmingham, UK: University of Birmingham.

Cauldwell, R., \& Hewings, M. (1996). Intonation rules in ELT textbooks. English Language Teaching Journal, 50(4), 327334.

Cheng, W., Greaves, C., \& Warren, M. (2008). A corpus-driven study of discourse intonation. Philadelphia, PA: John Benjamins.

Chun, D. M. (2002). Discourse intonation in L2: From theory and research to practice. Philadelphia, PA: John Benjamins.

Clennell, C. (1997). Raising the pedagogic status of discourse intonation teaching. English Language Teaching Journal, 51(2), 117-125.

Creswell, J. W. (2013). Research design: Qualitative, quantitative, and mixed methods approaches. London, UK: Sage.

Denzin, N. K., \& Lincoln, Y. S. (2002). The qualitative inquiry reader. Thousand Oaks, CA: Sage.

Du Bois, J. W., Schuetze-Coburn, S., Paolino, D., \& Cumming, S. (Eds.).(1992). Santa Barbara papers in linguistics, 4: Discourse transcription. Santa Barbara, CA: University of California Press.

Ghana Statistical Service (2012). 2010 population and housing census: Final report. Accra, Ghana: Ghana Statistical Service.

Goh, C.C.M. (1994). Exploring the teaching of discourse intonation. Regional English Language Centre Journal, 25(1), 77-98. 
Goh, C.C. M. (1998). The level tone in Singapore English. English Today, 14(1), 50-53.

Goh, C.C. (2005). Discourse intonation variants in the speech of educated Singaporeans. In Deterding, D., Brown, A. \& Low E.L. (Eds.), English in Singapore: Phonetic research on a corpus (pp. 104 -114). Singapore: McGraw Hill.

Gumperz, J. J. (1982). Discourse strategies. Cambridge, UK: Cambridge University Press.

Hewings, M. (1995). Tone choice in the English intonation of nonnative speakers. International Review of Applied Linguistics, 33(3), 251-265.

Kachru, B. B. (1996). The paradigms of marginality. World Englishes, 15(3), 241-255.

Koranteng, L. A. (1992). The Use of Non-Segmental Features in Ghanaian English. (M. A. Thesis). University of Ghana, Legon, Ghana.

Koranteng, L. A. (2006). Ghanaian English: A description of its sound system and phonological features. (PhD Thesis). University of Ghana, Legon, Ghana.

O'Grady, G. (2010). A grammar of spoken English discourse: The intonation of increments. London, UK: Continuum.

Ono, T., \& Couper-Kuhlen, E. (2007). Increments in cross-linguistic perspective: Introductory remarks. Pragmatics, 17(4), 505-512.

Pickering, L. (1999). An analysis of prosodic systems in the classroom discourse of native speaker and nonnative speaker teaching assistants. (PhD Dissertation). University of Florida, USA. Retrieved from Proquest Digital Dissertations. (UMI 9946032).

Pickering, L. (2001). The role of tone choice in improving ITA communication in the classroom. TESOL Quarterly, 35(2), 233255.

Pickering, L. (2009). Intonation as a pragmatic resource in ELF interaction. Intercultural Pragmatics, 6(2), 235-255

Schiffrin, D. (1994). Making a list. Discourse Processes, 17(3), 377 408.

Sey, K. A. (1973). Ghanaian English: An exploratory survey. London, UK: Macmillan.

Tench, P. (1996). The intonation systems of English. London, UK: Cassell.

Walker, G. (2004). On some interactional and phonetic properties of increments to turns in talk-in-interaction. In E. Couper-Kuhlen \& C. E. Ford (Eds.), Sound Patterns in Interaction (pp. 147169). Amsterdam, The Netherlands: John Benjamins. 


\section{Appendix A}

\section{Transcription Conventions}

Tone unit boundaries

Onset syllables

// //

Nuclear syllable

UPPERCASE

Lengthening

UPPERCASE

Length of pause

Tone

Overlap

Breath

$: /::$

[]

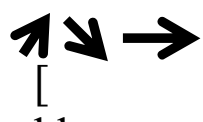

hh

Submitted: May 29, 2016/Published: October 31, 2016 